\title{
Chloramphenicol Combined with Ampicillin in Treatment of Typhoid
}

\author{
F. DE RITIS， G. GIAMMANCO， G. MANZILLO
}

British Medical fournal, 1972, 4, 17-18

\section{Summary}

Fifty out of 100 patients with typhoid fever, matched for age, stage of illness, and degree of fever, were treated with chloramphenicol and the other $\mathbf{5 0}$ were treated with chloramphenicol combined with ampicillin. The febrile period was shortened by up to $29 \%$ in patients treated with the combined drugs compared with those given only chloramphenicol. Moreover, no patient on combined therapy had a fabrile relapse, whereas two relapses occurred among patients treated with chloramphenicol only. We conclude that chloramphenicol and ampicillin together are better than chloramphenicol alone in the treatment of typhoid fever.

\section{Introduction}

The study reported here was designed to find out whether treatment of typhoid fever with chloramphenicol combined with ampicillin, when compared with treatment with chloramphenicol alone, shortened the febrile period of the disease, diminished the incidence of febrile relapses, and lessened the number of patients who became carriers.

\section{Patients and Methods}

Typhoid fever is almost endemic in the Neapolitan area and is often associated with eating raw or poorly-cooked shellfish. The 100 patients in the present study were mostly sporadic cases from the same district occurring within a period of a few months, and they were selected from those admitted to hospital within 10 days of onset of the febrile period and matching for age and degree of fever. They were allocated alternately to two treatment groups (A and B) until 50 patients had been treated in each group.

The mean age of the groups was $21 \cdot 1 \pm 10 \cdot 8$ and $21 \cdot 1$ \pm 11.3 years respectively and the interval from the onset of fever to the start of treatment 7.2. \pm 2.2 and 6.7 \pm 2.1 days. The peak temperature on the day of admission of patients in both groups was $38.9 \pm 0.6^{\circ} \mathrm{C}$. The diagnosis of typhoid fever was made on clinical evaluation corroborated by either a positive blood or faeces culture or a positive Widal reaction, or by a combination of two or of all three tests.

Salmonella typhi was cultured from the blood of 27 patients in group $A$ and of 40 in group $B$ and from the faeces of 15 in group $A$ and of 22 in group $B$. When the Widal reaction was the only corroboratory test used a minimum titre of $1: 200$ was generally required. It was positive at that titre in 19 cases in group $\mathbf{A}$ and in three in group $\mathbf{B}$.

Patients in group A were given only chloramphenicol and patients in group B were given a combination of chloramphenicol and ampicillin.

Institute of Clinical Medicine, University of Naples, 2nd Medical School, F. Naples

Institute of Hygiene, University of Palermo Medical School, Palermo G. GIAMMANC̄O, M.D., Assistant Prcfessor

Department of Infectious Diseases, Cotugno Hospital, Naples

G. MANZILLO, M.D., Chief of Department
The dose of chloramphenicol given to adults in both groups (mean weight $70 \mathrm{~kg}$ ) was $2 \mathrm{~g} / 24 \mathrm{hr}$ by mouth in four divided doses at six-hour intervals. Children aged under 12 were given doses proportional to their body weight. Chloramphenicol was continued in all adults until they had received a total of $30 \mathrm{~g}$ and in all children under 12 until they had received a total of $24 \mathrm{~g}$.

The dose of ampicillin in addition to chloramphenicol given to patients in group B was $4 \mathrm{~g} / 24 \mathrm{hr}$ intramuscularly in four divided doses at six-hour intervals in adults and a dose proportional to body weight in children aged under 12. Ampicillin was continued for at least seven days in all cases and always until two days after defervescence.

\section{Results}

Two patients in group A had a febrile relapse, one after eight and the other after 22 days, but no relapses were observed among the patients in group B treated with ampicillin and chloramphenicol.

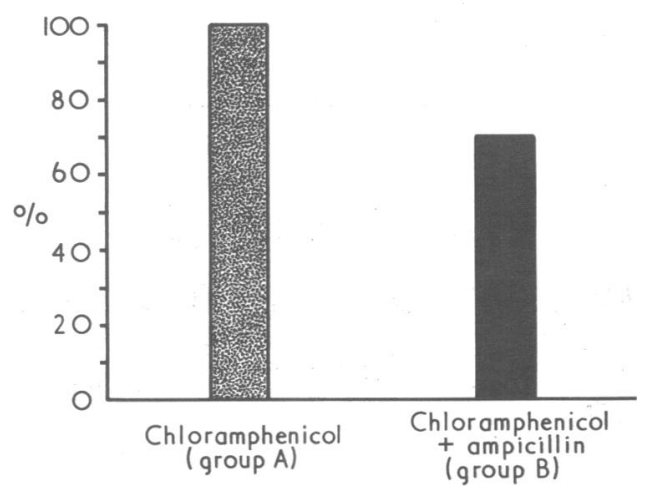

FIG. 1-Mean duration of fever from start of treatment in group B shown as a percentage of that in group $\mathbf{A}$.

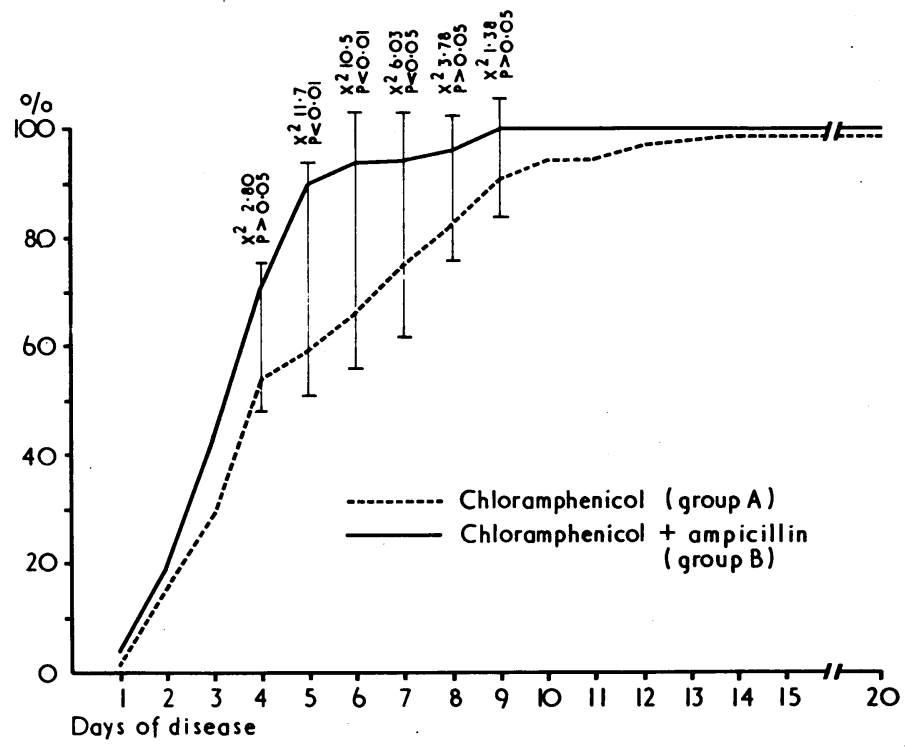

FIG. 2-Daily percentage of patients without fever in the two treatment groups. 
The mean duration in days of fever after the start of treatment was 5.4 (S.D. \pm 3.2 ) in group $A$ and 3.9 (S.D. \pm 1.7 ) in group B, with ranges of 1-15 and 1-9 days respectively. The difference is statistically significant $(t=3.087 ; \mathrm{P}<0.05)$. The mean lengths of the febrile period in the two groups are compared in Fig. 1. The daily percentage of patients in each group without fever is shown in Fig. 2. The difference is statistically significant at the fifth, sixth, and seventh days.

The biological characteristics, phage type, biochemical type, and minimal inhibitory concentration of chloramphenicol and ampicillin for the 35 strains of salmonella recovered from 31 patients in group $A$ and for the 61 strains from 43 patients in group $B$ are given in the Table. As can be seen, they were mostly phage type A.

Biological Characteristics of Strains of Salm. typhi Isolated from Blood or of Faeces of Patients with Typhoid Fever

\begin{tabular}{|c|c|c|c|c|c|c|}
\hline \multirow{2}{*}{$\begin{array}{l}\text { Treatment } \\
\text { Group }\end{array}$} & \multirow{2}{*}{$\begin{array}{c}\text { No. of } \\
\text { Strains } \\
\text { Isolated* }\end{array}$} & \multicolumn{2}{|c|}{$\begin{array}{c}\text { Minimum Inhibitory } \\
\text { Concentration } \\
(\mu \mathrm{g} / \mathrm{ml})\end{array}$} & \multirow{2}{*}{$\begin{array}{c}\text { Phage Type } \\
(\%)\end{array}$} & \multicolumn{2}{|c|}{$\begin{array}{c}\text { Biochemical Type } \\
(\%)\end{array}$} \\
\hline & & $\underset{\text { cillin }}{\text { Ampi- }}$ & $\begin{array}{l}\text { Chloram- } \\
\text { phenicol }\end{array}$ & & I & II \\
\hline $\mathbf{A}$ & $35 \dagger$ & $\leqslant 0.4$ & $\leqslant 4$ & $\left\{\begin{array}{lr}\mathrm{A}_{1} & 85 \cdot 7 \\
\mathrm{D}_{1} & 5 \cdot 7 \\
\mathrm{C}_{4} & 5 \cdot 7 \\
\mathrm{~B}_{2} & 2.9\end{array}\right\}$ & $97 \cdot 2$ & $2 \cdot 8$ \\
\hline B & $61 \ddagger$ & $\leqslant 0.4$ & $\leqslant 4$ & $\left\{\begin{array}{lr}\mathrm{A}_{1} & 91.8 \\
\mathrm{D}_{1} & 4.9 \\
\mathrm{~F}_{4} & 1.6 \\
\text { NT } & 1.6\end{array}\right\}$ & $88 \cdot 6$ & 11.4 \\
\hline
\end{tabular}

* In some patients Salm typhi was isolated from both blood and faeces. † Isolated from 31 patients.

Isolated from 43 patients.

Biochemical type according to Christensen (1938): I = xylose +, arabinose -; II $=$ xylose - , arabinose - .
Because of the susceptibility of all the strains of salmonella to either antibiotic, a comparison of their susceptibility to the combined antibiotics with their susceptibility to each antibiotic separately was impracticable. Such a comparison would be possible only after inducing a state of relative resistance to either antibiotic, thus making determination of susceptibility to the combination more meaningful. This work is in progress.

No carriers of Salm. typhi were found in cultures of faeces from patients in either group 30 to 45 days after defervescence.

\section{Conclusion}

Treatment of typhoid fever with combined chloramphenicol and ampicillin shortened the febrile period after the start of therapy by up to $29 \%$ compared with patients treated with chloramphenicol alone. The difference was statistically significant. The standard deviation of the mean of the length of the febrile periods from the start of treatment was significantly smaller for patients in group B than for those in group A. Ranges were also narrower for group B (1-9 days) than for group A (1-15 days). No febrile relapses were observed in group B but there were two in group A.

Chloramphenicol and ampicillin combined, therefore, seem to be better than chloramphenicol alone in the treatment of typhoid fever.

\section{Reference}

Christensen, M. (1938). Fournal of Hygiene, 38, 688.

\title{
Nomograms for Calculation of Oxygen Consumption and Respiratory Exchange Ratio
}

\author{
J. F. NUNN
}

British Medical fournal, 1972, 4, 18-20

\section{Introduction}

Measurement of oxygen consumption by determination of the composition and volume of expired air (the Douglas bag method)

\section{Summary}

Nomograms have been prepared whereby the respiratory exchange ratio may be derived from the concentrations of carbon dioxide and oxygen in expired gas and oxygen consumption from the volume and oxygen concentration of expired gas; they apply only to patients breathing room air. The nomogram for the respiratory exchange ratio has an error of less than 0.01 , which is the limit of visual discrimination on the nomogram. The nomogram for oxygen consumption has an error of standard deviation $7.73 \mathrm{ml} / \mathrm{min}$. This error may be substantially reduced by excluding cases with a respiratory exchange ratio outside the range $0 \cdot 70-0 \cdot 93$. Under these conditions the maximum error was $10 \mathrm{ml} / \mathrm{min}$, which is acceptable for a wide range of clinical purposes.

\footnotetext{
Division of Anaesthesia, Clinical Research Centre, Harrow, Middlesex

J. F. NUNN, M.D., PH.D., F.F.A. R.c.s., Head of Division
} is much more accurate than the closed circuit spirometrict echnique, and is also much more convenient when combined with the measurement of such respiratory parameters as physiological dead space and pulmonary venous admixture. The method thus has much to commend it for routine use in departments concerned with lung function.

Calculation of oxygen consumption $\left(\dot{\mathrm{V}}_{2}\right)$ is usually based on the following equation when the inspired gas is room air:

$$
\begin{aligned}
& \dot{\mathrm{VO}}{ }_{2}(\mathrm{ml} / \mathrm{min})=\frac{\text { Volume collected }(1 .)}{\text { Collection time }(\mathrm{min})} \\
& \times \mathrm{f}\left(\frac{0.2093\left(1-\mathrm{F}_{\overline{\mathrm{EO}}}{ }_{2}-\mathrm{FECO}_{2}\right)}{0.7904}\right)-\mathrm{F}^{-} \overline{E O}_{2} \quad \ldots
\end{aligned}
$$

where $\mathrm{f}=$ the factor required to convert gas volumes measured at ambient temperature and pressure saturated (ATPS) to the equivalent volume under conditions of standard temperature and pressure dry (STPD), $\mathrm{FE}_{2}=$ oxygen concentration in mixed expired gas, and $\mathrm{FECO}_{2}=$ carbon dioxide concentration in mixed expired gas (Pappenheimer et al., 1950).

Solution of this equation is easy with a programmable calculating machine but is tedious when manual methods are used. We have therefore considered the magnitude of the error 